\title{
Urinary tract infection in febrile convulsions
}

\author{
Philip Lee, Kate Verrier Jones
}

\begin{abstract}
A retrospective review of the casenotes of 403 children admitted to hospital with febrile convulsions was performed to estimate the frequency of symptomatic urinary tract infection and examine medical practice in making this diagnosis. A total of $228(56 \%)$ children had urine cultured: 150 bag specimens, 76 clean voided samples, and two suprapubic aspirates. There were 13 'probable' and six 'possible' infected urine samples together representing $5 \%$ of the whole study population $(n=403), 8 \%$ of those having urine cultured $(n=228)$, and $12 \%$ of those providing uncontaminated urine samples $(n=155)$. Those with first febrile convulsions and those aged under 18 months were more likely to have urine examined. Practices varied significantly between different hospitals. These results suggest that there has indeed been a need for practice guidelines, and that further audit of practice is required to assess their impact.
\end{abstract}

The lack of a universal policy in the management of urinary tract infection in childhood has been recognised in a recent report from the Royal College of Physicians (RCP). ${ }^{1}$ Recommendations were made regarding management, research, and audit. In particular the early diagnosis and treatment of urinary tract infection in febrile children with possible concomitant illness was emphasised. This is important as urinary infection in early childhood may cause renal scarring, especially if there is a delay in treatment. This may lead to later hypertension, reduced glomerular filtration rate, and renal failure. ${ }^{2}$ In women it may lead to pregnancy induced hypertension and complicated delivery. ${ }^{4}$ Vesicoureteric reflux may be present in a third of infants with urinary tract infection and has implications for other family members also. ${ }^{5}$

There is, therefore, a serious penalty for failing to diagnose and treat urinary tract infection. At the same time a false positive diagnosis will unnecessarily subject a healthy infant to inappropriate investigations including micturating cystourethrography. For these reasons it is essential to develop policies that facilitate early and accurate diagnosis. This study was carried out before the RCP report and aimed to assess the local paediatric approach to establishing, or excluding, the diagnosis of urinary tract infection in a group of febrile children with convulsions. At the same time an estimate of the frequency of urinary tract infection in this population would give an indication of the size of the problem. This group was chosen because of its close correspondence to the age group at greatest risk of developing renal scarring and because fever is the commonest, and possibly most significant, symptom in infants and young children with urinary tract infection. ${ }^{6}$

\section{Patients and methods}

Data were collected by retrospective analysis of casenotes of children under 6 years old admitted to three hospitals in South Glamorgan with a diagnosis of febrile convulsion. Cases were identified through the Hospital Activity Analysis during the period 1 January 1986 to 31 December 1987. The notes were examined for evidence of fever, details of the fit, the child's medical history, the cause of fever, types of investigation performed, and for evidence of exclusion of urinary tract infection.

\section{STATISTICS}

The data were processed using a VAX 8530 computer to generate frequency distributions and results compared using the $\chi^{2}$ test.

\section{DEFINITIONS}

Febrile convulsion included any ictal episode, simple or complex, of any duration associated with a febrile illness from the history. A simple febrile convulsion was defined as a generalised convulsion, not focal, lasting less than 15 minutes with no neurological sequelae and occurring only once within 24 hours. A complex convulsion was any other fit. ${ }^{7}$ Probable urinary tract infection was diagnosed when a pure growth of greater than $10^{5}$ colony forming units $(\mathrm{cfu}) / \mathrm{ml}$ was obtained. Possible urinary tract infection was diagnosed when a pure growth of a single organism between $10^{4}$ and $10^{5} \mathrm{cfu} / \mathrm{ml}$ was obtained.

Urine samples showing a mixed growth of organisms more than $10^{3} \mathrm{cfu} / \mathrm{ml}$ were deemed to be contaminated and urine samples which grew less than $10^{3} \mathrm{cfu} / \mathrm{ml}$ were considered to be sterile.

\section{Results}

During the 24 month period studied there were 13801 paediatric medical admissions to the three hospitals in South Glamorgan of which $432(3 \cdot 1 \%)$ were attributed to febrile convulsions. Notes were retrieved for $403(93 \%)$; there were 169 girls (42\%) and 234 boys (58\%) with a mean age of 24 months (range 1-71 months). 
Table 1 Discharge diagnoses made by clinicians to account for febrile convulsion

\begin{tabular}{lr}
\hline Diagnosis & $\begin{array}{c}\text { No of } \\
\text { cases }\end{array}$ \\
\hline Upper respiratory tract & \\
infection & 97 \\
Tonsillitis & 76 \\
Otitis media & 47 \\
'Viral illness' & 30 \\
Gastroenteritis & 19 \\
Chest infection & 15 \\
Urinary tract infection & 7 \\
Chickenpox & 7 \\
Measles & 7 \\
Bacteraemia & 5 \\
After vaccination & 4 \\
Mumps & 2 \\
Encephalitis & 2 \\
Abscess & 1 \\
Meningitis & 1 \\
Blocked ventriculoperi- & \\
toneal shunt & 1 \\
None & 82 \\
Total & 403 \\
\hline
\end{tabular}

Altogether 252 admissions were for first convulsions; 110 had complex fits; 31 children had abnormal neurological findings or developmental delay. There were 185 episodes of first time, simple, febrile convulsions in children with normal neurology having a recorded fever of $37.5^{\circ} \mathrm{C}$ or greater. There was no seasonal variation in admission rate.

One hundred and ninety one children underwent blood tests which included white cell count, haemoglobin, glucose, calcium, urea and electrolyte concentrations, virological studies and blood culture. One hundred and thirty two children had radiography of the chest and/or skull. Swabs were taken from the ears, nose, throat, or skin in 182 children; 65 children had cerebrospinal fluid examined.

A total of 228 urine samples were cultured: $150(66 \%)$ were collected into sterile plastic bags; $76(33 \%)$ were clean voided or midstream samples; and two (1\%) were collected by suprapubic aspiration.

Table 1 shows the clinical diagnoses made at discharge. Table 2 shows the results of urine culture. Urine samples were contaminated in 56 of $163(34 \%)$ bag specimens and 17 of $86(20 \%)$ of clean voided samples. Twenty six of 112 girls (23\%) and 47 of 150 boys (31\%) provided contaminated samples and 56 of the 73 contaminated samples $(77 \%)$ were from children under 24 months. The two suprapubic aspirates were sterile. Table 3 shows clinical details and results of urine culture and microscopy in the children with urinary tract infection: 13 'probable' and six 'possible'. The figure displays the frequency of urinary tract infection which varies according

Table 2 Results of urine culture

\begin{tabular}{lcc}
\hline & $\begin{array}{l}\text { No(\%) total } \\
\text { study } \\
\text { population } \\
(n=403)\end{array}$ & $\begin{array}{l}\text { No(\%) } \\
\text { with first, simple } \\
\text { febrile convulsions* } \\
(n=185)\end{array}$ \\
\hline Urine examined & $228(56)$ & $116(63)$ \\
Urine not examined & $175(44)$ & $69(37)$ \\
Total urinary tract infection & $19(5)$ & $9(5)$ \\
Probable & $13(3)$ & $6(3)$ \\
Possible & $6(2)$ & $3(2)$ \\
Sterile urine & $136(34)$ & $73(39)$ \\
Contaminated urine & $73(18)$ & $34(18)$
\end{tabular}

${ }^{*}$ These children had normal neurology.

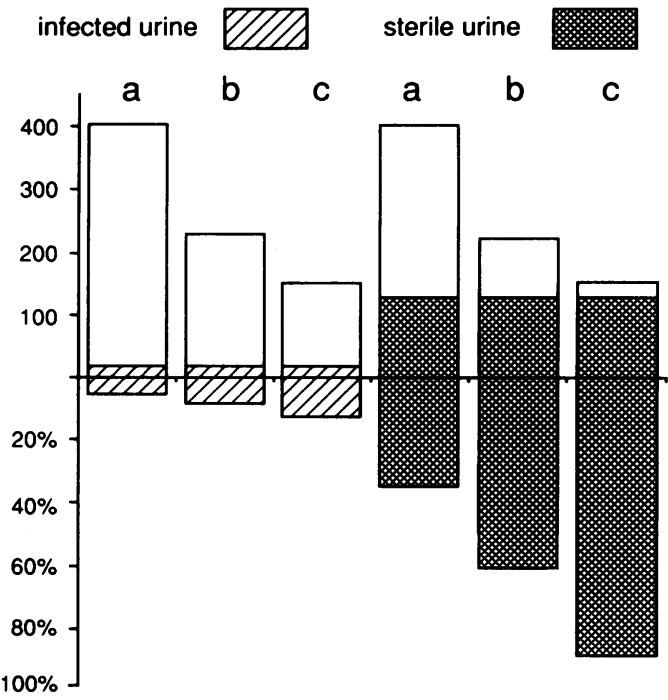

Numbers (above line) and percentages (below line) of infected and sterile urine samples in relation to $(a)$ whole group $(n=403),(b)$ those children in whom urine was cultured $(n=228)$, and (c) those children in whom the urine was not contaminated $(n=155)$.

to the reference group. The mean age was 22 months (range 7-54 months) with seven boys and 12 girls. Escherichia coli was the infecting organism in $84 \%$ of cases. Children under 18 months $\left(\chi^{2}=8.31, \mathrm{p}<0.001\right)$, those having their first fit $\left(\chi^{2}=23.95, \mathrm{p}<0.001\right)$, and children having one or more other tests performed $\left(\chi^{2}=\right.$ $62.6, \mathrm{p}<0.001)$ were more likely to have urine cultured. There were also significant differences between all three hospitals with $74 \%, 59 \%$, and $42 \%$ of admissions respectively having urine examined and cultured $\left(\chi^{2}=23.86, p<0.001\right)$. Urine culture was not influenced by sex, developmental delay, type of seizure, or presence of an obvious cause for the fever.

\section{Discussion}

The need to consider the diagnosis of urinary tract infection in every febrile infant or young child has been emphasised by the report from the RCP. ${ }^{1}$ This is important for several reasons. First, urinary tract infection in infancy and

Table 3 Characteristics of children with probable and possible urinary tract infection

\begin{tabular}{|c|c|c|c|c|c|c|c|}
\hline $\begin{array}{l}\text { Case } \\
\text { No }\end{array}$ & Sex & $\begin{array}{l}\text { Age } \\
\text { (months) }\end{array}$ & Organism & $\begin{array}{l}\text { Growth } \\
\text { (cfu/ml) }\end{array}$ & Microscopy" & Sample type & Repeat sample \\
\hline $\begin{array}{r}1 \\
2 \\
3 \\
4 \\
5 \\
6 \\
7 \\
8 \\
9 \\
10 \\
11 \\
12 \\
13 \\
14 \\
15 \\
16 \\
17 \\
18 \\
19\end{array}$ & $\begin{array}{l}\mathrm{F} \\
\mathrm{F} \\
\mathrm{F} \\
\mathrm{F} \\
\mathrm{M} \\
\mathrm{F} \\
\mathrm{M} \\
\mathrm{F} \\
\mathrm{M} \\
\mathrm{F} \\
\mathrm{F} \\
\mathrm{F} \\
\mathrm{F} \\
M \\
M \\
\mathrm{~F} \\
M \\
M \\
\mathrm{~F}\end{array}$ & $\begin{array}{r}7 \\
54 \\
16 \\
26 \\
18 \\
13 \\
8 \\
12 \\
15 \\
12 \\
26 \\
31 \\
42 \\
37 \\
25 \\
9 \\
16 \\
16 \\
45\end{array}$ & $\begin{array}{l}E \text { coli } \\
E \text { coli } \\
E \text { coli } \\
E \text { coli } \\
P \text { seudomonas } \mathrm{sp} \\
E \text { coli } \\
E \text { coli } \\
E \text { coli } \\
E \text { coli } \\
E \text { coli } \\
E \text { coli } \\
\text { Streptococcus faecalis } \\
E \text { coli } \\
E \text { coli } \\
E \text { coli } \\
E \text { coli } \\
P \text { roteus } \mathrm{sp} \\
\text { E coli } \\
\text { E coli }\end{array}$ & $\begin{array}{l}>10^{5} \\
>10^{5} \\
>10^{5} \\
>10^{5} \\
>10^{5} \\
>10^{5} \\
>10^{5} \\
>10^{5} \\
>10^{5} \\
>10^{5} \\
>10^{5} \\
>10^{5} \\
>10^{5} \\
6 \times 10^{4} \\
6 \times 10^{4} \\
6 \times 10^{4} \\
6 \times 10^{4} \\
6 \times 10^{4} \\
6 \times 10^{4}\end{array}$ & $\begin{array}{c}10 \\
40 \\
50 \\
0 \\
0 \\
10 \\
50 \\
30 \\
\text { Not known } \\
\text { Not known } \\
\text { Not known } \\
0 \\
100 \\
0 \\
0 \\
0 \\
0 \\
0 \\
0\end{array}$ & $\begin{array}{l}\text { Bag } \\
\text { Clean void } \\
\text { Bag } \\
\text { Clean void } \\
\text { Bag } \\
\text { Bag } \\
\text { Bag } \\
\text { Bag } \\
\text { Bag } \\
\text { Bag } \\
\text { Bag } \\
\text { Bag } \\
\text { Clean void } \\
\text { Clean void } \\
\text { Bag } \\
\text { Bag } \\
\text { Bag } \\
\text { Bag } \\
\text { Clean void }\end{array}$ & $\begin{array}{l}\text { No } \\
\text { Yes } \\
\text { After treatment } \\
\text { No } \\
\text { No } \\
\text { Yes } \\
\text { Yes } \\
\text { Yes } \\
\text { No } \\
\text { After treatment } \\
\text { No } \\
\text { No } \\
\text { No } \\
\text { No } \\
\text { No } \\
\text { No } \\
\text { No } \\
\text { No } \\
\text { No }\end{array}$ \\
\hline
\end{tabular}


Table 4 Studies of symptomatic urinary tract infection in children

\begin{tabular}{llllcc}
\hline Author $(s)$ & Type of study & $\begin{array}{l}\text { Age of } \\
\text { population }\end{array}$ & Setting & $\begin{array}{c}\text { No of children } \\
\text { studied }\end{array}$ & $\begin{array}{c}\text { Incidence of } \\
\text { urinary tract } \\
\text { infection }(\%)\end{array}$ \\
\hline North $(1963)^{16}$ & Prospective & $0-13$ years & Hospital & 32 & $3-6$ \\
Leape and McEachen $(1974)^{17}$ & Prospective & ? & Outpatient & 156 & 19 \\
Roberts et al $(1983)^{18}$ & Prospective & 0-2 years & Collaborative, hospital & 501 & $4 \cdot 1$ \\
Krober et al $(1983)^{19}$ & Prospective & Under 3 months & Hospital & 182 & 11 \\
Bauchner et al $(1987)^{20}$ & Prospective & 0-5 years & Outpatient & 664 & $1 \cdot 7$ \\
Bonadio $(1987)^{21}$ & Retrospective & O-1 year & Hospital & 265 & $5 \cdot 5$ \\
\hline
\end{tabular}

early childhood often gives rise to fever but rarely gives rise to localising symptoms. ${ }^{6}$ Secondly, appropriate antimicrobial treatment to alleviate symptoms is unlikely to be given unless the correct diagnosis has been made. Thirdly, delays in diagnosis will not only prolong the duration of symptoms but also increase the risk of acquired renal scarring. ${ }^{8}$ Finally, there may be an underlying abnormality such as obstruction or vesicoureteric reflux, ${ }^{9}$ which increases the risk of recurrence of infection as well as the risk of acquired renal scarring. ${ }^{10}$ Such lesions will only come to light if appropriate investigation including ultrasound of the kidneys and micturating cystourethrography are later carried out.

Appropriate management with antibiotic prophylaxis and surgery ${ }^{11}$ combined with parental counselling on the symptoms and management of recurrent infection have an important part to play in minimising the risk of further acquired renal damage. Furthermore, the fact that renal damage and severe systemic illness develop most often in the youngest children, ${ }^{12}$ the group in whom localising symptoms are invariably absent, means that it is particularly important to culture urine in infancy. Unfortunately the collection of urine for culture from young children before the age of toilet training is difficult and time consuming and there is a high contamination rate, particularly when plastic collecting bags are used. ${ }^{13}$ The more reliable methods, catheterisation and suprapubic aspiration, are more invasive and also have disadvantages. After catheterisation there is a significant risk of developing infected urine unless antibiotics are given prophylactically and the risk of having a negative tap on suprapubic aspiration deters some doctors from routine use of this procedure.

Much of the work on the significance of the colony count was done by Kass who studied asymptomatic pregnant women and outlined criteria that would give a low risk of false positive results. ${ }^{14}$ Work in children suggests that lower counts may be indicative of infection. ${ }^{15}$ In view of the risk of renal damage if there is a delay in treatment it is more important to reduce the chance of false negative results. However, many laboratories use the same criteria for reporting infection in all age groups. For these reasons many paediatricians rely heavily on the presence of organisms and pus cells on direct microscopy for the initiation of treatment, adjusting the antibiotic if necessary when culture results are available. Difficulties arise when a contaminated sample is reported or where the results of culture are not in agreement with the diagnosis made at microscopy.
In this study, the proportion of children detected with bacteriuria was between $5 \%$ and $12 \%$. The true proportion is dependent on the number of false negative and positive results and the number of children in whom urine was not cultured but who nevertheless had undetected urinary tract infection (see figure). These results are comparable with those of other studies (table $4^{16-21}$ ). The absence of an increase in the first six months of life in this study is likely to be due to the small number of infants of this age developing febrile convulsions. The use of antiseptic in some studies to wash the perineum may have the effect not only of lowering the contamination rate but also of masking true infection by inhibition of bacterial growth. ${ }^{20}$

This study has confirmed the importance of urinary tract infection as a cause of systemic febrile illness in early childhood even in the absence of localising symptoms. It has also shown that paediatricians did not have a consistent policy to establish or exclude the diagnosis of urinary tract infection in every febrile child. The discovery that there were significant differences between the three hospitals in South Glamorgan suggests that local opinion is an important factor influencing paediatric practice. The limitations of urine culture with unacceptably high contamination rates, particularly in young children, suggest that greater reliance should be put on urine microscopy and that paediatricians should be more willing to collect urine by suprapubic aspiration in infants with unexplained fever. Smyth et al had previously pointed out inconsistencies amongst paediatricians in their investigation and long term management of childhood urinary tract infection. The RCP's guidelines have provided the impetus for further research and audit and should eventually lead to more satisfactory medical practice in this important area. Its impact must be evaluated critically in the future by further studies.

We thank the Laura Ashley Foundation for financial support and Mrs Christa George for secretarial assistance.

1 Working Group, Research Unit, Royal Colege of Physicians in childhood. $\mathcal{F} R$ Coll Physicians Lond 1991;25:36-42.

2 Jacobson SH, Eklof O, Eriksson CG, Lins LE, Tidgen B, Winberg J. Development of hypertension and uraemia after pyelonephritis in childhood. BMF 1989;299:703-6.

3 Verrier Jones K, Asscher AW, Verrier Jones ER, Mattholie $\mathrm{K}$, Leach $\mathrm{K}$, Thompson GM. Glomerular filtration rate in schoolgirls with covert bacteriuria.. $B M \mathcal{F}$ 1982;285: 1307-10.

4 Sacks S, Verrier Jones K, Roberts R, Leddingham JGG, Asscher AW. Outcome of pregnancy in women with childhood bacteriuria. Lancet 1987; ii:991-4.

5 Aggarwal VK, Verrier Jones K. Vesicoureteric reflux: screening of first degree relatives. Arch Dis Child 1989;64: ing of firs 
6 Smellie JM. Medical aspects of urinary infection in children. J R Coll Physicians Lond 1967;i:189-96.

7 Addy DP. Nosology of febrile convulsions. Arch Dis Child 1986;61:318-20.

8 Smellie J, Ransley PG, Normand ICS, Prescod N, Edwards $D$. Development of new renal scars: a collaborative study. BMF 1985;290:1957-60.

9 Ring E, Zobel G. Urinary tract infection and malformations of urinary tract in infancy. Arch Dis Child 1988;63:818-20.

10 Smellie JM, Edwards D, Hunter N, Normal ICS, Prescod N. Vesico-ureteric reflux and renal scarring. Kidney Int 1975;

11 White RHR. Management of urinary tract infection and vesicoureteric reflux in children. $B M \mathscr{F}$ 1990;300:1391 -4 .

12 Berg U, Johansson SB. Age as a main determinant of renal functional damage in urinary tract infection. Arch Dis Child 1983;58:963-9.

13 Hardy JD, Furnell PM, Brumfitt W. Comparison of sterile bag, clean catch and suprapubic aspiration in the diagnosis of urinary tract infection in early childhood. Br $\mathcal{f}$ Urol of urinary tract
$1976 ; 48: 279-83$.
14 Kass EH. Asymptomatic infection of the urinary tract. Trans Assoc Am Physicians 1956;69:56-64.

15 Hellerstein $S$. Recurrent urinary tract infection in children. Pediatr Infect Dis 1982;1:271-81.

16 North AF. Bacteriuria in children with acute febrile illnesses. f Pediatr 1963;63:408-11.

17 Leape LL, McEachen WH. Office urine cultures in pediatric practice. Postgrad Med 1974;56:177-82.

18 Roberts KB, Charney E, Sweren RJ, Ahonkai VI, Bergman DA. Urinary tract infection in infants with unexplained fever: a collaborative study. $\mathcal{F}$ Pediatr 1983;103:864-7.

19 Krober MS, Bass JW, Powell JM, Smith FR, Seto DS. Bacterial and viral pathogens causing fever in infants less than 3 months old. Am $\mathcal{J}$ Dis Child 1985;139:889-92.

20 Bauchner H, Philipp B, Dashefsky B, Klein JO. Prevalence of bacteriuria in febrile children. Pediatr Infect Dis $\mathcal{f} 1987$ 6:239-42.

21 Bonadio WA. Urine culturing technique in febrile infants. Pediatr Emerg Care 1987;3:75-8.

22 Smyth RL, Berman L, Valman HB. Current practice in managing urinary tract infections in children. $B M \mathcal{F} 1988$; 287:1516-7.

Infant feeds: the oops factor

The oops factor must be one of the most frequent of historical regulators. It is a prime cause of wars, disasters, plague, and famine. Fairly recent memory serves to show that it may bring about the demise of prime ministers, ensures a rapid turnover of cabinet and lesser ministers, has forced the resignation of one US president, and has been prominent in the administrations of at least two others. In medicine there is the grand international oops factor such as leads to babies being born without limbs or people dying of AIDS and there are the local and personal oops potentials we all battle with from day to day. (In one respect clinical audit is a procedure for the avoidance or modification of oops.) Infant formula feeding is a procedure replete with oops potential, so much so that the manifest safety of most infant formulas must be a source of considerable relief (phew! factor). Notable oops outbreaks have given rise to pyridoxine deficiency in the 1950s, and phosphate and solute overload in the 1960s and 70s.

Between March 1978 and August 1979 two soy based formulas marketed in the US and one in Spain were grossly lacking in chloride. Babies fed on these formulas fed poorly, failed to thrive, became weak and lethargic, vomited, and developed a metabolic alkalosis with a low serum chloride and potassium. When given extra chloride they rapidly recovered from their acute illness. ${ }^{1}$

Reports of follow up of some of these children have shown cognitive and language impairments. Now Thomas Kaleita, Marcel Kinsbourne, and John Menkes (Developmental Medicine and Child Neurology 1991;33:626-35) have described a distinctive syndrome of cognitive and behavioural impairments in 11 of 13 children. All children were seen because of parental concern about their development after they were fed on the chloride deficient milk and when examined they were aged 5 to 10 years. Two children had global cognitive impairment. The 11 were all of normal overall intelligence but showed an expressive language disorder, 'attention deficit hyperactivity disorder', and visual-motor, and fine motor problems. This grouping of features is unusual in other children with cognitive and behavioural deficiencies.

Makes you think, doesn't it? 